\title{
Uma corda sobre o abismo: diálogo entre Lima Barreto e Nietzsche
}

\author{
Carmem Lúcia Negreiros de Figueiredo
}

Muito já se disse da apropriação dos escritos de Nietzsche por tendências políticas de esquerda ou de direita, especialmente quanto às noções de super-homem, associada ao nazismo e do racismo. Mas como um escritor e intelectual das primeiras décadas do século XX poderia discutir temas presentes em obras como Assim falava Zaratustra e $A$ origem da tragédia, entre outras?

Leitor de Nietzsche, o escritor Afonso Henriques de Lima Barreto (1881-1922) estabelece um diálogo tenso com muitos conceitos e idéias do filósofo, e isso pode ser percebido, em tons diversos, desde as anotações de leituras, artigos, crônicas até a composição de alguns de seus principais personagens de ficção. Neste artigo, pretende-se refletir sobre uma das vertentes desse diálogo, aquela que repensa os limites do humano, além das certezas da razão, das regras da moral ou das peias da religião.

Embora o teor dessas afirmações possa ser apreendido no melhor da sua produção ficcional, nas crônicas ou artigos, é através da possibilidade de construção de um provável itinerário de criação literária que buscaremos a força e a coerência de suas reflexões. Trata-se do estudo e análise de uma coleção de recortes e revistas, mescladas a anotações manuscritas, versando sobre temas de ordem íntima (a parte mínima), política, cultura, literatura. O título escolhido pelo autor para essa coleção - Retalhos - indica a sua organização em fragmentos, relegada pela crítica tradicional. Além disso, deu-lhe uma forma linear de diário, tratando-se de um relato do cotidiano sob um olhar seqüencial. Parcialmente publicados sob o título de Diário íntimo, esses fragmentos encontramse na Seção de Manuscritos da Biblioteca Nacional.

Tornar significativo um conjunto de registros fragmentários implica propor uma leitura do cotidiano e da História que, longe de um relato cronológico e linear dos aconteci- 
"(Schlegel, Friedrich. O dia. leto dos fragmentos. Trad. apresentação e notas de Márcio Suzuki. São Paulo: Iluminuras, 1997: 58.) mentos, recolhe os discursos, as promessas, mas também as confidências e o silêncio que podem vir das esquinas, dos bares, das portas de hospício, das massas anônimas. Quem fala - um intelectual - e de onde fala tornam instigantes esses fragmentos. Para lê-los, portanto, e sem impor-lhes a organização já feita pela crítica tradicional, optei por estabelecer, no lugar de hipóteses, roteiros de leitura, numa associação entre os temas registrados em Retalhos - recortes e anotações manuscritas - e os temas encontrados nas obras ficcionais, ou não, do escritor. Nesse processo, cada fragmento pode repetir, complementar, contradizer, pontuar todos os outros, numa sintaxe não linear, de ritmo variado. Como numa reação em cadeia, o fragmento permite um movimento simultâneo de síntese e deslocamento, podendo abarcar uma síntese de temas e idéias e, ao mesmo tempo, deslocar questões para a obra literária ou para os textos jornalísticos recortados, associados ao contexto histórico-cultural. Dar conta, enfim, de uma crítica sistemática e coerente, numa tentativa de esquivar-se da maquinaria positivista, sem perder o rigor da reflexão. Mas como analisar o registro memorialístico de um colecionador de retalhos? Quando levamos em conta a definição de memória de F. Schlegel, que a apresenta como um sistema de fragmentos - fragmentário na forma e na matéria, ao mesmo tempo subjetivo e objetivo* - , observamos que os Retalhos guardam essa duplicidade de, na origem, serem inteiramente subjetivos - representam a escolha e seleção do que lembrar, recortar, fixar - e, em sua composição, configurarem um painel de temas histórico-culturais e literários. Resultam do plural interior do sujeito que recorda e remetem a um vasto contexto, permitindo ler o colecionador e o mundo que ele desenha, ao montar e compor a sua coleção de retalhos. Implodem, nessa perspectiva, as representações da história e do eu como uma narração ordenada cronologicamente - típico das posturas historicistas -, por adotarem o princípio de similaridade próprio da memória, na subversão do ordenamento tranqüilo do discurso estabelecido, bem como deixam de propor uma narração de sucessos (ou de insucessos) para sugerir também imagens, e não um percurso. É importante considerar, no entanto, que história e temporalidade não são negadas nesse processo, mas se concentram no 
próprio objeto de recordação, isto é, constitui-se uma relação intensiva com o tempo e do tempo no objeto, e não a sujeição a uma ordem exterior, geral e universal imposta aos objetos e recortes particulares. Dito de outra forma, em vez de se procurar a ordenação linear de um percurso, distribuindo seqüencial e cronologicamente os fragmentos, escolhe-se aqui abordá-los como uma síntese paradigmática entre tempo e espaço, uma imagem-tempo ou uma ruína, na concepção de Walter Benjamin*. O mesmo princípio, portanto, que norteou a sua composição - a montagem - também orienta a leitura de Retalhos. Por isso, o método de crítica é o desvio: desvio da linearidade cronológica e da causalidade da narração sucessiva, inerentes à concepção historicista; desvio para o salto, para a intercalação de imagens, recortes, textos literários ou não, a construir um painel de retalhos, a partir de roteiros de leitura.

São muitos os registros de cartas a crônicas, nos quais o escritor Lima Barreto se apresenta como um colecionador de retalhos. "Tenho retalhos de jornais franceses que cortei há anos para me documentar", afirma em uma de suas crônicas do volume Feiras e mafuás*. Afinal, argumenta o escritor, em "Vida urbana”, "quando queremos ler um jornal com cuidado, fazemos descobertas portentosas”* Além da coleção, que reunia recortes de jornais em cadernos, com o título de Retalhos, o escritor ainda recebia outros mais de presente, de pessoas próximas conhecedoras de seu interesse.

No entanto os recortes não são reunidos por acaso e, na sua maioria, são objeto de pesquisa em torno de temas, idéias, tendências e fontes diversas, que vão da literatura e vida literária à política, aos costumes, a festas e ritos populares, à modernização de hábitos e cenários, às notícias bizarras das crônicas e reportagens, como um peculiar e original recurso de observação crítica do cotidiano e da cultura. Entre os recortes preferidos estão os "a pedidos" do Jornal do Commercio: “não deixo nunca de ler os 'a pedidos' e recortá-los, arquivando os retalhos. [...] neles vou buscar elementos para estudo da vida doméstica, comercial e sentimental da nossa sociedade"*.

O resultado mais evidente desse método de observação crítica, e até criação, está na constituição do volume de crônicas, denominado pelo autor Marginália; no fim da primeira
"(Benjamin, Walter. "Charles Baudelaire, um lírico no auge do capitalismo". Em: Obras Escollhidas III. São Paulo: Brasi. liense, 1989: 85.)
'(Lima Barreto, Afonso Hen. riques de. Feirasemafuás. São Paulo: Brasiliense, 1956: 193.)

(Lima Barreto, Afonso Hen. riques de. Vida Urbana. São Paulo: Brasiliense, 1956:207.) 
crônica, que trata da questão dos poveiros ${ }^{1}$, com dura crítica ao nacionalismo, explica o seu método de investigação e análise dos temas de que serão feitas as crônicas apresentadas no volume.

Era tal a falta de uma segura orientação nos que se digladiavam, que só tive um remédio para estudá-la mais tarde: cortar as notícias de jornais, colar os retalhos num caderno e anotar à margem as reflexões que esta e aquela passagem me sugerissem. Organizei assim uma "marginália" a esses artigos e notícias. Uma parte vai aqui."

Apesar da insistência do escritor em expor o método de observação e leitura do mundo pelo fragmento, pela seleção, pela pesquisa e por um tipo de 'arquivamento' peculiar, a crítica enxergou no título do volume de crônicas uma síntese da opção pela retórica que representa a "marginália", a dos empobrecidos e marginais do contexto social. Esse método promove uma produtiva desordem nos acontecimentos porque reúne objetos de espaços e tempos descontínuos, recorta conjuntos compreensíveis, aproxima as lembranças, quando recorda, por afinidades independentes de uma relação causal. $\mathrm{O}$ confronto entre a história dos sujeitos - nos jornais mesclados a recortes de livros - e os relatos oficiais constitui não só uma oportunidade privilegiada para o escritor (e para o leitor de Retalhos) repensar paradigmas da interpretação histórica como também, a partir de formulações e outras experiências, possibilitar a emergência de novos sujeitos. Não se trata, pois, de incluir uma narrativa sobre um tema, dentro da narrativa histórica já elaborada, mas da inserção de diferentes agentes, igualmente participantes do processo histórico, que pouco foram ouvidos e considerados, sugerindo uma reescrita de aspectos da história a partir dos retalhos.

Que idéias dessa produtiva desordem de recortes podemos destacar como um pequeno exemplo de roteiro de leitura? Há um fragmento de notas sobre Nietzsche interessante e útil, que entre outros aspectos, exemplifica o critério cronológico de seleção dos 'retalhos' para organizá-los na forma de diário - publicado, nas Obras de Lima Barreto, em 1956.

${ }^{1}$ Pescadores portugueses de Póvoa do Varzim que exerciam o monopólio da pesca em alto-mar sem se naturalizarem brasileiros. 
Trata-se de uma anotação feita, no alto da folha de caderno, a lápis e com ótima letra, acompanhada de recortes variados de jornais com referências de datas diversas: retalhos de jornais de 1905, 1907 e 1917. Um fragmento de Assim falava Zaratustra, conforme a referência ao final da nota, feita pelo escritor.

Voluptuosidade, és para os corações livres qualquer coisa inocente e livre, as delícias do jardim terrestre transbordante de gratidão do futuro presente*.
Volupté - c'est pour les coeurs libres quelque chose d'innocent et de libre, le bonheur du jardin de la terre, la débordante reconnaissance de l'avenir pour le présent*.
' (Tradução de José Mendes ções de Ouro, 1967: 175.)

"(Lima Barreto, Afonso Henriques de. Diário Íntimo. São Paulo: Brasiliense, 1956: 190.)

Há ainda, entre os fragmentos, uma anotação, um trecho em francês, também de Assim falava Zaratustra, colada no sentido vertical, que parece ter sido arrancada de outro caderno, sem acompanhamento de recortes de jornal e, talvez por isso, o biógrafo tenha publicado em Diário Íntimo, com a observação "sem data", dentro do capítulo correspondente ao ano de 1911 .

O homem é corda estendida entre o animal e o Super-homem; uma corda sobre o abismo; perigosa travessia, perigoso caminhar, perigoso olhar para trás, perigoso tremer e parar*
L'homme est une corde tendue entre la bête et le surhumain une corde sur l'abîme. Il est dangereux de passer au delà, dangereux de rester en route, dangereux de regarder en arrière, frisson et arrêt dangereux.*
' (Tradução de José Mendes de Souza. Ob. cit.: 25.)

"(Lima Barreto, Afonso Hen. riques de. Diário Íntimo. Ob. cit.: 162.)

Embora sejam diversas as anotações extraídas de obras de Nietzsche, como A origem da tragédia e $O$ anticristo, é interessante observar o movimento desses temas na obra de Lima Barreto. Pretende-se discutir aqui algumas das referências em crônica, artigo e conto.

Leitor e intelectual atento às discussões contemporâneas, quer se trate de sociologia, quer de filosofia, política ou arte, Lima Barreto transforma a sua permanência no Hospital Central do Exército ${ }^{2}$ em motivo para ler crônicas e artigos do que denomina "sociologia de revistas". No quarto do hospi-

${ }^{2}$ Lima Barreto esteve internado por dois meses, de 4 de novembro de 1918 a 5 de janeiro de 1919, para tratar a clavícula fraturada. 
(Lima Barreto, Afonso Henriques de. Bagatelas. São Pau lo: Brasiliense, 1956: 105.)

(Lima Barreto, Afonso Hen riques de. Impressões de Leitura. São Paulo: Brasiliense, 1956: 119.) tal, escreve a crônica "Da minha cela" e, com o pretexto de comentar essa experiência de quase prisioneiro, registra suas observações acerca dos temas apresentados, sem profundidade e coerência, por articulistas de periódicos a que tinha acesso no hospital. Registra, nessa perspectiva, a crítica a um artigo cujo autor denomina velharias as teorias maximalistas e anarquistas às quais opõe, como novidade, o pensamento de Nietzsche. Com ironia, Lima Barreto lamenta profundamente a falta de memória e de leitura do articulista, flagrando o seu desconhecimento das obras de teor políticofilosófico das quais se diz comentador. Além de apresentar a cronologia do período de produção dos textos de Nietzsche, corrige o mau uso da expressão super-homem, como só um leitor constante poderia fazer.

Compete-me dizer afinal ao festejado articulista que o Zaratustra, do Nietzsche, dizia que o homem é uma corda estendida entre o animal e o super-humano - uma corda sobre um abismo. Perigoso era atravessá-la; perigoso, ficar no caminho; perigoso, olhar para trás. Cito de cor, mas creio que sem falsear o pensamento.*

Se o uso grotesco, oportunista e redutor dos conceitos extraídos das obras de Nietzsche, nas páginas de jornais e revistas, é duramente criticado por Lima Barreto, a aplicação equivocada dessas idéias em textos de ficção torna-se imperdoável para o escritor. No volume Impressões de leitura, apresenta, com sarcasmo, um trecho do romance de estréia de Albertina Berta (conhecida militante do feminismo), no qual a autora compara o "super-homem" de Nietzsche ao Nirvana búdico e ao Paraíso cristão, para tornar público "o absurdo de tal coisa”. Expõe, assim, as palavras da autora para exemplificar a moral do "super-homem" e, a seguir, esta observação com ênfase no contra-senso.

Aos primeiros, às naturezas plenas (os 'Super-Homens'), a esses seres privilegiados, artistas do pensamento e da ação, que sabem governar-se, manejar as paixões em proveito próprio (tomem nota), desviar as reações, ela (a tal moral dos Super-Homens) tudo permite para a sua existência, o seu equilíbrio na vida universal: aventuras, incredulidades, repouso, o próprio excesso, a impiedade, a rudeza" $[\ldots]$.

É possível admitir sujeito de tal moral digno do Paraíso ou do Nirvana?*

No entanto, no mesmo movimento de irritação e crítica, Lima Barreto resume a sua opinião sobre o autor de Zaratustra, 
num misto de repúdio e demonstração de conhecimento dos temas do filósofo.

Não gosto de Nietzsche; tenho por ele ojeriza pessoal. Acuso-o, a ele e ao Esporte, como causadores do flagelo que vem sendo a guerra de 1914 .

Ele deu à burguesia rapace que nos governa uma filosofia que é a expressão de sua ação. Exaltou a brutalidade, o cinismo, a amoralidade, a inumanidade e, talvez, a duplicidade.*

Se fôssemos considerar linearmente estas "impressões de leitura", certamente encerraríamos aqui qualquer possibilidade de reflexão acerca do diálogo do escritor carioca com a obra de Nietzsche. Tudo ficaria reduzido à simplificadora recusa veemente do pensamento político, do conceito de guerra, no dizer de Antonio Candido, "propagandístico e ingênuo", que procura encontrar no pensamento do filósofo o precursor do nazismo. Estaria Lima Barreto preso, de alguma forma, a essa interpretação exclusiva? Seria próprio de um escritor extremamente interessado "em fazer de seu instrumento artístico um veículo de difusão das grandes idéias do tempo"* uma abordagem redutora de um pensamento tão complexo? E mais, não estaria o pensamento de Nietzsche alicerçando "as grandes idéias do tempo"?

Para fugir às armadilhas tentadoras de influências e generalizações, é preciso prosseguir com a leitura das obras do escritor. Há, entre elas, um conto intitulado "Como o "homem' chegou" (a palavra homem está grafada com aspas simples pelo autor), que se abre com uma epígrafe de Assim falava Zaratustra: "Deus está morto; a sua piedade pelos homens matou-o. Nietzsche", e apresenta-se contaminado de expressões próprias da obra do filósofo.

O personagem título - o 'homem' - caracterizado por "assomos d'alma e anseios de pensamento"* era um ente pacato que se atirou ao cálculo, à inteligência pura, à Matemática, e vivia solitário numa chácara, na companhia apenas do velho pai. O descompasso de suas atitudes - consideradas esquisitas por 'piedosos' familiares, cujos parâmetros eram outros sábios, ligados à política vulgar e às negociatas - justificou a fama de louco e, conseqüentemente, o pedido de prisão. Pedido endossado por parentes, ansiosos por curá-lo, providos de "estultice congênita".

\footnotetext{
${ }^{3}$ Escrito em 18/10/1914.
} 
O conto caminha de uma despretensiosa abertura, com forte acento satírico à placidez, monotonia e mediocridade de uma delegacia ${ }^{4}$ do interior do Amazonas, para a construção, gradativa, de níveis de crueldade e violência extremas, com situações absurdas nascendo da banalidade do cotidiano, com o fim de causar impacto sobre o leitor. Na segunda parte do conto, políticos e sábios importantes planejam a prisão do pacífico, inofensivo e solitário estudioso tido como louco e a sátira é superada, aos poucos, pela ironia mordaz. Seus algozes se constituem deslocados e com conhecimento incompatível com a função que exercem, a ponto de, ao calcular no mapa a distância entre Rio e Manaus, interpretarem linearmente as convenções cartográficas, e sintetizarem: "apenas um palmo e meio". A engenhosidade desses personagens também desenhou o terrível veículo para transportar o prisioneiro, da região Norte do país até a capital da Primeira República.

Assim, uma masmorra de ferro ambulante - "blindada, chapeada, couraçada"* - foi bizarramente levada do Rio para o interior do país, seguida de soldados fortemente armados, na expedição em busca do "homem" perigoso. O momento da prisão vale a pena registrar.

Desgraçadamente não encontrou o homem perigoso. Recolheu a expedição a quartéis; e, certo dia, quando de passeio, por acaso, foi parar a um café do centro comercial. Todas as mesas estavam ocupadas; e só em uma delas havia um único consumidor. A esta, ele sentou-se. Travou por qualquer motivo conversa com o mazombo; e, durante alguns minutos, aprendeu com o solitário alguma cousa. Ao despedirem-se, foi que ligou o nome à pessoa, $\mathrm{e}$ ficou atarantado sem saber como proceder no momento. A ação, porém, lhe veio prontamente; e, sem dificuldade, falando em nome da lei e da autoridade, deteve o pacífico ferrabrás em um dos dois bailéus do cárcere ambulante. *

E a caravana, formada por "naturalista, antropologista e etnografista da escola do conde de Gobineau", seguiu viagem e "sob um sol de fogo, o carro solavancava pelos maus caminhos; e o doente, à míngua de não ter onde se agarrar, ia ao encontro de uma e outra parede de sua prisão couraçada"*.

${ }^{4}$ Sua rotina de celas vazias só se interrompia por queixas de casos de defloramento. 
Recebendo vaias da população por onde passava, ainda ouvia as expressões: "Ó maluco! Ó maluco!".

Como os condutores da expedição não sabiam "se essa espécie de doente comia", resolveram consultar seus superiores, que, alegando ser o prisioneiro bastante perigoso, decidiram que não seria conveniente retirá-lo da masmorra ambulante para suas necessidades. Já vale observar aqui o parâmetro esdrúxulo para definir 'perigoso': o pensamento independente vinculado a uma atitude solitária que, mesmo em silêncio, produz comparações incômodas e alimenta suspeitas. Além disso, por ser tão curta a viagem (Manaus está a apenas "um palmo e meio" do Rio), não haveria necessidade de alimentá-lo. Assim, monotonamente, prosseguiu a viagem por entre serras e rios, entrecortada por algumas peripécias, como um ataque de jacarés que deixou ferido um animal de carga, fazendo-o perder uma das patas dianteiras.

Sarou-lhe a ferida não se sabe como e o animal não deixou de acompanhar a caravana. Às vezes distanciava-se; às vezes, aproximava-se; e sempre a pobre alimária olhava longamente, demoradamente, aquele forno ambulante, manquejando sempre, impotente para a carreira, e como se lastimasse de não poder auxiliar eficazmente o lento reboque daquela almanjarra pesadona."

Durante quatro anos, o carro continuou "a sua odisséia com o acompanhamento do burro, sempre a olhá-lo longamente, infinitamente, demoradamente, cheio de piedade imponente"*. Sai de cena a sátira e a ironia introduz o absurdo, que retira as rígidas marcas temporais e espaciais, aumentando a tensão à medida que se aprofundam a indiferença e cegueira dos condutores da viagem. Chegou o lúgubre carro, finalmente, às ruas do Rio de Janeiro, cercado de urubus atraídos pelo mau cheiro do cadáver, mas acompanhado, sempre, de seu "manco e compassivo burro a manquejar-lhe à sirga"* Apresenta-se, portanto, o impossível produzido pela estrutura autoritária, pautada pela obediência acrítica, cuja fachada é a do saber dito técnico, progressista e racional, alimentada pelo paternalismo de relações pessoais e subserviência.

A única expressão de piedade e humanidade se transfere, no texto, ao animal que acompanha o séqüito. Através do olhar "compassivo" do burro, o leitor pode simultaneamente experimentar as possibilidades da dor humana e conhecer 
"(Candido, Antonio. "O por. tador". Ob. cit: 198.) até onde podem chegar os níveis de degradação e barbárie. Ao produzir o horror com a monotonia da viagem, a indiferença dos acompanhantes - que cavoucavam formigas ou discutiam regras de gramática - e a expropriação absoluta do 'homem' prisioneiro, o conto atinge a consciência do leitor, que, ao se defrontar com personagens que excedem os limites do possível, pode redefinir os próprios limites e parâmetros com os quais lê o mundo, percebendo a fragilidade que os reveste. E se o olhar do animal está comprometido com o instante, isto é, preso à imediatidade da cena que presencia, o olhar do leitor poderá projetar essa experiência para a história, para a crítica da cultura, visualizando o irracional que o espreita no cotidiano.

Nessa perspectiva, ao construir o conto, Lima Barreto também permite a aproximação com as críticas das bases do humanismo, uma discussão que inflamaria os intelectuais na segunda metade do século XX, depois dos horrores revelados pelos sobreviventes da barbárie da Segunda Guerra. Isto porque, em seus textos de ficção, já manifesta a inquietação quanto aos riscos das leituras lineares de pensamentos filosóficos ou das certezas da razão teórica.

Quando Nietzsche propõe o "super-homem" (ou sobrehomem) em Zaratustra, apresenta uma finalidade quase propedêutica como indicação de que o homem deve superar a si mesmo. Sugere, por isso, uma certa dureza e abolição da autocomplacência, "posto que justiça e bondade repousam sobre a energia com que superamos as injunções, as normas cristalizadas, tudo enfim que tende a imobilizar o ser em posições já atingidas e esvaziadas de conteúdo vivo"*

Nada tem a ver, portanto, com o sentido de raça superior utilizado pelo nazismo; esse novo homem compreende o divino como imanência do próprio ser. Se há uma luta permanente entre a vida que se afirma e a que vegeta, esta prende o homem aos valores rotinizados da civilização cristã e burguesa. O super-homem de Nietzsche pode ser visto como uma crítica ao humanitarismo do século XIX e como uma indicação da complexidade do homem, que as visões racionalistas e simplificadoras ainda teimavam em defender nas primeiras décadas do século XX.

Alguns intérpretes, contudo, consideram que esse homem superior proveio do desenvolvimento da humanidade num 
sentido darwinista e que, por isso, pode ser visto como o último resultado da concepção evolucionista. Entendimento possível devido ao item 3 do "Prólogo" de Zaratustra. Nele, o super-homem se apresenta numa perspectiva linear de tempo, teleológica, de processo finalizado*. Tal controvérsia demonstra a dificuldade de interpretação que não leva em conta o fato de ser "Zaratustra" um personagem dramático (seu princípio fundador é o dionisíaco) que passa por metamorfoses e que, no início de sua trajetória, ainda se encontra distante dos aspectos mais relevantes da filosofia de Nietzsche. Dessa forma, o super-homem não é um conceito que pode ser congelado por situar-se no movimento das fases de experiência do personagem. Nessa perspectiva, se o homem não deve mais ser considerado como meta, e sim como ponte, transição - "uma corda estendida" -, como uma semente de esperança a ser plantada, o super-homem não se configura como uma realidade, mas como uma exigência.*

Estaria Lima Barreto dialogando com a abordagem crítica que considera a linearidade e o evolucionismo na concepção do super-homem? Ao inverter, pela sátira, os pólos de conteúdo, isto é, quando projeta a piedade e solidariedade no animal e desumaniza o homem, estaria o escritor ironizando o sentido de evolução em direção ao aprimoramento humano? Pode haver esperança num mundo sem "deus"?

Se a expressão "morte de Deus" é a constatação da ruptura que a modernidade introduz na história da cultura, com o desaparecimento de valores absolutos, das essências e dos fundamentos divinos ele também pressupõe a abertura para o desaparecimento de toda vontade, a ausência de todo valor, o fim do amor, da criação e do anseio. O contraponto a esse processo seria configurar ao super-homem o sentido da terra*, isto é, pensar o homem como criador de valores, para assunção de nossa humanidade.

Lima Barreto põe essa possibilidade sob exame em "Como o 'homem' chegou”, suspeita da hipótese de o homem ser a 'corda', a transição para o super-homem. Nesse sentido, mostra-se contemporâneo dos debates que ainda hoje acontecem em torno de tais reflexões. No conjunto da sua obra de ficção, apenas com o personagem "historiador artista ${ }^{5}$ Gonzaga de

\footnotetext{
${ }^{5}$ Trata-se do personagem do romance Vida e Morte de M. J. Gonzaga de Sá.
}

"(Machado, R. Zaratustra: traJédia nietzschiana. Rio de 2001.)

'(Casanova, Marco Antonio. "A religião da terra: o lugar do sagrado no pensamento de Friedrich Nietzsche". Em: Pinheiro, P. Barrenechea, M.; deà terra: P. (orgs.). A fidelidade à terra: arte, natureza e poli2003.) 
"Nietzsche, Friedrich. As sim falava Zaratustra. Tradu ção de José Mendes de Sou za. Prefácio de Geir Campos. Rio de Janeiro: Edições de Ouro: 48 .)

"(Lins, Daniel. "A história da cultura é a história da cruel dade". Em: Feitosa, C. Barre nechea, M.: Pinheiro, P. (orgs.) A fidelidade à terra: arte, na. tureza e política. Ob. cit.)

"(Lima Barreto, Afonso Hen riques de. "Como o 'homem' chegou". Ob. cit.:288.)
Sá” talvez vejamos a tentativa de representação do pensamento livre, que voa e dança sobre o abismo.

Contraditoriamente, no livro Assim falava Zaratustra, encontra-se a expressão "Não é com cólera, mas com riso que se mata”, observação que pode contribuir para tornar mais complexo e tenso o diálogo entre Lima Barreto e Nietzsche.

Ora, também permeia a obra do filósofo a reflexão de que a história da cultura é a história da crueldade*, e o mais cruel, antes de tudo, é o pensamento. Pensar implica, entre outras coisas, diferenciar, associar, identificar. $\mathrm{O}$ pensamento invade nossa alma e pode provocar um domínio e/ou abertura sem limites de nossas sensações e afetos. Em "Como o 'homem' chegou” uma série de personagens obedientes, dominados pela repetição automática, carregados de dogmas e preconceitos - cegos, pois, ao desigual, singular e diferente são apresentados com os recursos da caricatura. Esta concilia a agudeza da ironia com o senso profundo do grotesco, pela fixação de detalhes ou situações ridículos e deslocados. Ao desenhar croquis literários, Lima Barreto constitui personagens como o "doutor Barrado" - "um catita do lugar, cheiroso, apurado no corte das calças" - e enfatiza a particularidade física dominante com o acréscimo de uma atitude fora do lugar, a fim de acentuar o ridículo das atitudes. Resume-se, assim, a preocupação do "doutor Barrado": ser êmulo do Pe. Vieira e aproveitar o tempo (o tempo da viagem com o prisioneiro no carro) para "firmar bem as regras de colocação dos pronomes, sobretudo a que manda que o 'que' atraia o pronome complemento"* .

Um traço de ironia também perpassa o discurso do narrador, e esta é uma arma do escritor satírico, quando finge desenvolver um completo relato das atividades científicas do "doutor Tucolas", estudioso do crânio das formigas.

[...] logo examinava bem o crânio do inseto, procurava-lhe os ossos componentes, enquanto não fazia uma mensuração cuidadosa do ângulo de Campar ou mesmo de Cloquet* .

Com esse recurso, critica o saber que alija o discernimento e o conhecimento que estimula a capacidade de reproduzir (em vez de criar), quer em formas de memorização, quer pela atitude não questionadora e preconceituosa. Da caricatura, e com os recursos da sátira, o escritor produz a ironia mordaz que possibilita o absurdo sob a forma do completo automatis- 
mo no cumprimento de ordens irracionais, a absoluta indiferença diante da dor alheia e a cegueira em face da diferença do outro.

Dessa maneira, produzindo o riso, Lima Barreto mostra como o pensar se torna cruel quando oblitera os sentidos e afetos, enrijece a sensibilidade e ensurdece a alma. Se Zaratustra, com a dança, desestabiliza a aparente imobilidade das coisas, a rigidez do pensamento, a fixidez das palavras, para que as idéias ganhem leveza, o escritor apresenta distintas perspectivas acerca do perigo dos dogmas, das certezas, das crenças, especialmente aquelas que endeusam a razão. Evidencia (e pressente!) o perigo do cientificismo autoritário e violento que estudará crânios e genes em experiências macabras com seres humanos. E, pondo sob suspeita toda e qualquer certeza, reencontra, na tensão do diálogo, o pensamento de Nietzsche.

O mais interessante a observar, considerando apenas o conto "Como o 'homem' chegou", é a inquietação que provoca no leitor quando desvenda a fera e os instintos que habitam a personalidade humana, suscitando esta questão: as promessas da ciência, da técnica e mesmo da arte poderão auxiliar o 'homem'? Poderá este atravessar o abismo?

A noção de humanidade veiculada pela ciência, pela política e pela filosofia ainda permanece incompleta, em revisão ou mesmo deslocada. Drástica se torna a constatação de que o conhecimento e o saber constituem muitas vezes peias, a pretexto de libertação.

Em tempos efervescentes de ordem e progresso, Lima Barreto projeta, portanto, a questão que ecoa até hoje: como poderá o ‘homem' fazer a travessia? De um lado, o saber, a ciência e a técnica não o aperfeiçoam; do outro, a ausência de compassividade e resignação também não o liberta. O escritor demonstra que não há dúvidas quanto ao abismo, mas mantém sob suspeita a capacidade da travessia, sem niilismo e com melancolia crítica. Foge das dicotomias que contaminaram seus contemporâneos, assim como influenciaram a recepção crítica de seus textos.

Sem apupos ou aplausos, Lima Barreto realiza um diálogo tenso e crítico com o autor de Assim falava Zaratustra. A composição de personagens, a demonstração de domínio das categorias importantes do pensamento, as citações de obras 
significativas e o registro de detalhada cronologia de sua publicação evidenciam a interlocução com Nietzsche.

Aspectos diversos poderiam ser analisados aqui para fundamentar textualmente e com profundidade o perfil desse diálogo entre o escritor e o filósofo. Este, todavia, é assunto para outro artigo. Procurou-se privilegiar a forma original de abordagem do tema, isto é, apresentar o diálogo a partir das pistas da escrita em retalhos, exemplificando apenas alguns aspectos da projeção de Nietzsche na obra de Lima Barreto. Há, com certeza, muitos personagens e diferentes situações ficcionais a serem iluminados pela análise que envolve o diálogo tenso e fecundo entre os autores.

É preciso esclarecer, no entanto, que utilizar a expressão diálogo não significa considerar a escrita de Lima Barreto produto direto da influência de uma tendência filosófica. Nietzsche é mais um dos muitos pensadores e filósofos cujas obras receberam atenção, crítica e reflexão do intelectual e escritor, atento à produção do pensamento teórico-crítico de sua época. Suas reflexões foram expressas em artigos, crônicas e nas próprias obras de ficção.

Ainda assim, a profundidade, a extensão e o impacto que resultam do contato de Lima Barreto com o pensamento de Nietzsche constituem motivo de investigação, perplexidade e estímulo para pesquisa. A riqueza desse diálogo envolve questões que iluminam principalmente as reflexões sobre o humanismo no mundo contemporâneo. 


\section{Carmem Lúcia Negreiros de Figueiredo}

Doutora em Teoria Literária pela Universidade Federal do Rio de Janeiro e professora de Teoria Literária da Universidade do Estado do Rio de Janeiro. Além de artigos, publicou o livro Trincheiras de sonho: ficção e cultura em Lima Barreto (Tempo Brasileiro, 1998) e coordenou, com Antonio Houaiss, o volume Lima Barreto, da Coleção Archives/UNESCO.

\section{Resumo}

A partir da coleção de 'retalhos' do escritor Lima Barreto (1881-1922), composta de recortes de jornais, revistas e livros, discute-se a especificidade desse tipo de memória e seus possíveis roteiros de leitura, associando os temas dos fragmentos à obra ficcional. Neste artigo, analisamos as pistas construídas pelo autor sobre o diálogo tenso com as obras de Nietzsche, especialmente na reflexão acerca das noções de humanidade.

\section{Abstract}

Through an analysis of different documents (newspapers, magazines and books) written by Lima Barreto (1881-1922), we discuss the specificity of this type of material, and possible guidelines for reading and linking the theme of fragments with fictional works. In this article, we analyse the signs left by the author, regarding the tense dialogue with Nietzsche's works, especially those containing a reflection about the notion of humanity.

\section{Résumé}

Dans la collection de fragments de Lima Barreto (1881-1922), composée d'extraits de journaux, de magazines et de livres, il y a une sorte de mémoire qui permet de les associer à la fiction de l'auteur. Cet article réfléchit aussi sur la tension entre les fragments de Lima Barreto et ses liaisons avec la philosophie de Nietzsche - surtout en ce qui concerne sa réflexion sur la notion d'humanité.

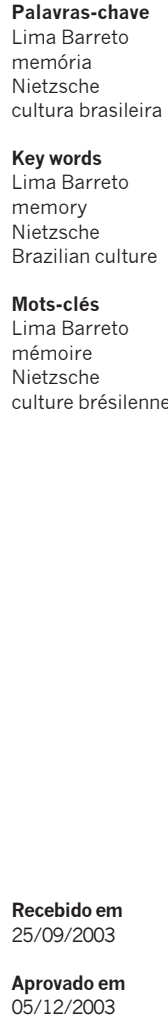

